\title{
Gestão de pessoas no setor público e a reprodução do discurso do setor privado
}

\author{
Marcus Vinicius Soares Siqueira e Ana Magnólia Mendes
}

A modernização da administração pública é um processo contínuo em que modelos e modismos gerenciais são constantemente implantados na expectativa de que a estrutura governamental possa atender de modo mais eficiente e eficaz às demandas sociais. Discute-se o tamanho do Estado, se deve ser onipotente ou minimalista, produtor ou catalisador; assim como são discutidas ações a serem desenvolvidas em parceria com a iniciativa privada e com organizações não governamentais, de modo a aumentar o espaço público não estatal, compartilhando com outros setores a responsabilidade pela prestação de serviços públicos. Além disso, mecanismos de consulta ao cidadão desenvolvem-se para que haja maior participação popular na formulação de políticas públicas, o que não deveria se restringir aos tecnocratas ou a pequenos grupos que detenham força política para influir no processo decisório. Percebe-se, pois, a importância da cidadania, outorgando-se ao cidadão papel de ampla relevância no desenvolvimento da administração pública, inclusive em termos de controle social. 
A gestão, inclusive de pessoas, tem papel singular na modernização do Estado, a fim de garantir a implementação adequada das mais diversas políticas públicas. Rever estruturas, torná-las mais leves, flexíveis e horizontalizadas são ações fundamentais para estabelecer uma máquina pública que cumpra efetivamente as suas funções. A reforma gerencial, a dita mudança do paradigma burocrático para o pós-burocrático ou gerencial, faz-se necessária, com a ressalva de que não seja apenas a transferência de tecnologias gerenciais do setor privado para o setor público. É necessário verificar o que faz, ou não, sentido ser importado do setor privado, tendo em vista a especificidade do setor público, que possui uma lógica própria. Há também a necessidade de se refletir sobre o impacto dessas mudanças na subjetividade do servidor público e o quanto a ideologia gerencial e a pressão da gestão atual podem prejudicar as relações de trabalho nas organizações públicas, ao invés de desenvolvê-las.

Estar atento às relações de trabalho nos órgãos públicos torna-se fundamental em processos de mudança cultural nos serviços prestados por servidores públicos. Ao se falar em modernização do Estado, depara-se com a ênfase dada em especial à construção de arcabouço gerencial que permita trazer do setor privado inspirações de técnicas e procedimentos administrativos que possam estabelecer um governo mais eficiente e eficaz, ou seja, que esteja preocupado com o aumento constante da produtividade e com a obtenção de resultados relevantes para a população. Nesse sentido, o New Public Administration pode ser considerado como um movimento em direção ao desenvolvimento dessas tecnologias gerenciais no setor público, implementadas, não raras vezes, a partir da idealização do que é implantado no setor privado. É necessário estabelecer determinados parâmetros de análise do impacto que essas estratégias possam gerar aos servidores públicos e, em último momento, à população.

O principal objetivo deste artigo é o de estabelecer uma análise crítica do discurso contemporâneo em gestão de pessoas, verificando como o discurso e a prática gerencialistas se reproduzem no setor público, sem que haja a devida análise do fator ideológico que permeia a gestão privada. Salienta-se, ainda, que quando falamos em gestão de pessoas não estamos nos limitando a uma área específica, à tradicional área de recursos humanos (RH), mas à gestão de pessoas de modo geral, alcançando todos os setores organizacionais.

Idealiza-se um discurso, sem que sejam estabelecidos os efeitos de novas filosofias de trabalho no dia a dia do servidor nas organizações públicas. Não se pretende ignorar a necessidade de maior eficiência e eficácia na prestação dos serviços públicos, mas não se pode perder de vista os efeitos decorrentes da obsessão pela produtividade e por resultados. Há, obviamente, a necessidade de a gestão estar orientada para resultados, mas não se pode estabelecer mecanismos de alcance desses objetivos que venham a deteriorar as relações de trabalho e inviabilizar a construção de um modelo próprio de gestão de pessoas no setor público, que pode resgatar alguns elementos do setor privado, servindo-lhe até mesmo de modelo. A orientação gerencialista está cada vez mais voltada para tarefas e menos para pessoas, precarizando o trabalho, desmotivando o servidor e fazendo com que as tarefas laborais pressionem cada vez mais o indivíduo, dificultando a criação de espaços de diálogo e de exercício da criatividade. Há necessidade de se retirar parte 
dos servidores da apatia em que se encontram, estabelecendo metas participativas, definindo incentivos materiais e simbólicos e proporcionando sentido para os trabalhos que realizam. Desse modo, a gestão de empresas privadas tem muito a oferecer, mas não pode ser percebida como fonte única de modelos de gestão. É necessário relativizar a importância dessa lógica de gestão no setor público e se iniciar a constituição de modelos próprios que possam ser efetivos e que promovam ambientes lúcidos de trabalho, sem pressão excessiva e com respeito à subjetividade do indivíduo, constituindo-se, até mesmo, em modelos para empresas privadas.

\section{Considerações acerca do imaginário organizacional moderno}

É necessário refletir sobre a gestão atual e o modelo de organização do trabalho, assim como sobre as relações laborais nas organizações contemporâneas. Gaulejac (2006) utiliza um termo apropriado ao caracterizar a gestão como "estando doente", ou seja, apesar de ser fundamental e ter o seu papel de organizar o mundo e racionalizar a produção, ela invade o mundo e pressiona o indivíduo, em vez de melhorar as relações humanas. A competitividade torna-se presente nos diversos campos de atuação humana, fazendo com que cada um procure, a partir da ação individual, e não coletiva, um lugar ao sol. A gestão privada é percebida como sendo a principal solução para o Estado e para o terceiro setor. Apenas existiria a efetivação do processo de modernização do setor público no momento em que a lógica do setor privado estivesse presente. Essas tecnologias gerenciais, que a partir da dimensão ideológica podem ser consideradas como práticas de controle e de coisificação do indivíduo, tornar-se-iam meros instrumentos à disposição do sistema produtivo. Gaulejac (2006, p.22) nos lembra que a gestão constitui um sistema de organização do poder que, "sob uma aparência objetiva, operacional e pragmática, é uma ideologia que traduz as atividades humanas em indicadores de desempenho, estes desempenhos em custos ou benefícios [...] ela constrói uma representação do humano como um

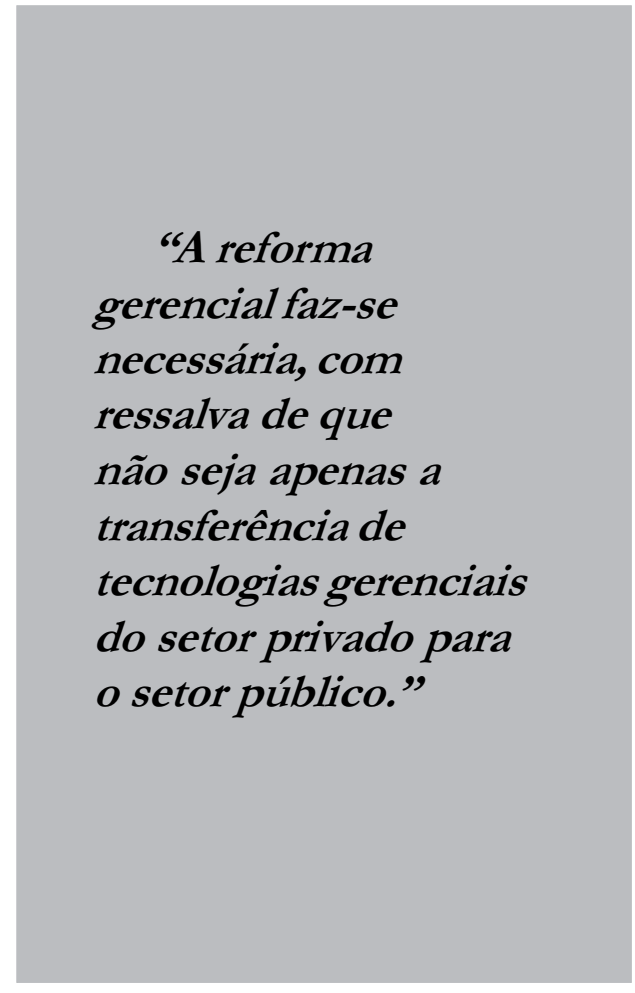

recurso a serviço da empresa, contribuindo, assim, para a instrumentalização".

Existe pressão pelo quantitativo, por números, pelo que possa ser mensurável, comparado e classificado. A flexibilização torna-se palavra-chave. Flexibiliza-se tudo, inclusive os contratos de trabalho, que se tornam cada vez mais temporários, instáveis e isentos de direitos aos trabalhadores. A estratégia de flexibilização é, 
segundo Chanlat (1996, p.16), diretamente responsável "pelo aumento do pessoal temporário externo, pelo desemprego de executivos e profissionais, pela diminuição de empregos estáveis e bem pagos e pelo aumento da precariedade e da exclusão". É necessário ser mais adaptável, ajustar-se às transformações do mercado, de modo a responder rapidamente às demandas dos consumidores. A rapidez é exigida do empregado, e não basta ser rápido, é necessário ser o mais rápido e o mais eficiente, pois o mercado de trabalho está continuamente mais enxuto, havendo espaço apenas para os que colocam o trabalho e a organização, na qual prestam serviços, em uma posição privilegiada em suas vidas. Enriquez (1997) nos traz a questão de que a ideia do trabalho enobrecer o homem está mais presente em nosso consciente e em nosso inconsciente, excluindo, muitas vezes, dimensões importantes da vida do sujeito. Além disso, podese dizer que "o valor de cada um é mensurado em função de critérios financeiros. Os improdutivos são rejeitados porque eles se tornam os inúteis do mundo. Assistimos ao triunfo da ideologia de realização de si mesmo. A finalidade da atividade humana não é mais fazer sociedade, ou seja, produzir um lugar social, mas explorar os recursos, materiais ou humanos". (GAULEJAC, 2006, p.57).

Nessa ideologia gerencialista e perversa, fundada no cálculo e na quantificação, a violência simbólica assume papel de relevância no momento em que os valores são colocados em segundo plano e apenas a racionalidade instrumental tem o seu espaço. As grandes empresas detêm poder cada vez mais intenso na sociedade atual, sendo que a riqueza de algumas empresas é maior do que o Poduto Interno Bruto (PIB) de parte significativa das nações. E a violência pode ser visualizada nas mais variadas dimensões, seja coletiva ou individual. Coletiva, no momento em que, em nome do "progresso", a empresa se percebe como detentora dos recursos ambientais e os usa de modo arbitrário; ou quando a empresa, que se tornou núcleo central da vida econômica de uma pequena cidade, transfere-se repentinamente para outro município, utilizando-se de justificativa técnica que venha a legitimar essa forma de violência. Individual, quando a pessoa é submetida a determinadas violências institucionais, como a de ser reificada, coisificada e considerada como peça inerte do processo produtivo, tendo sua subjetividade sequestrada pela empresa e vendo essas ações serem legitimadas por uma racionalidade discutível. Além disso, é difícil nomear um responsável por essa violência institucional, como menciona Levy (2001, p.78), ao dizer que "essas formas de violência não são personalizadas, encarnadas por sujeitos individuais ou por sujeitos coletivos. E suas vítimas, também, não são identificadas"; ou seja, o poder está nas regras, eximindo de culpa qualquer pessoa física que esteja envolvida em situações de violência.

A organização faz uso de determinadas operações no sentido de alcançar maior comprometimento afetivo do indivíduo, ou seja, joga-se com o amor, com a afetividade, de modo a adequar o indivíduo às propostas da empresa. Sedução e fascinação falam mais alto nos complexos jogos de poder e de desejo das organizações. A sedução pode ser considerada como uma modalidade de controle amoroso no momento em que uma das partes tem consciência de que o seduzido apenas está sendo alvo dos seus investimentos em virtude de um interesse de curto prazo; quando não houver mais 
necessidade, será lançado à fogueira, muitas vezes perplexo e desorientado. Da mesma forma, a fascinação auxilia na transformação do indivíduo em um elemento de determinada massa acrítica. Assim, ele dificilmente vai poder ou desejar emancipar-se frente aos processos de dominação no contexto organizacional. Há mais do que identificação do indivíduo à cultura; percebe-se, em determinadas situações, a substituição do ideal de ego do indivíduo pelo da organização, do imaginário do indivíduo pelos desejos e projetos organizacionais. Perder o senso crítico, colocar em risco a sua identidade e os seus sonhos são algumas das piores formas de violência a que o indivíduo pode-se sujeitar no mundo do trabalho.

Nesse contexto, o indivíduo se depara com alguns discursos organizacionais no que se refere à gestão de pessoas (SIQUEIRA, 2006): o discurso do superexecutivo de sucesso. $\mathrm{Na}$ busca desmedida do sucesso, $\mathrm{o}$ indivíduo se lança em um caminho de sacrifício, em que vale tudo. Dedica-se de tal forma ao trabalho e à organização que faz desses a sua principal razão para viver, os seus principais referenciais na vida. Um segundo discurso é o do comprometimento organizacional, em que se pretende uma fusão da identidade pessoal com a identidade funcional, fomentando-o para que assuma integralmente os valores, a cultura organizacional. A participação no processo decisório pode ser considerada como terceiro discurso organizacional em gestão de pessoas. No entanto, exige uma reestruturação das relações de poder nas organizações, deixando de ser algo que venha meramente referenciar decisões previamente tomadas, situações nas quais o indivíduo é instrumentalizado de modo a legitimar decisões já adotadas sem a sua participação. Esses são alguns dos vários discursos que podem ser identificados na gestão das organizações privadas e que têm sido reproduzidos no setor público como chave para o sucesso organizacional.

\section{Modelos de gestão em ação}

Observa-se na contemporaneidade o apogeu de modelos de gestão que são copiados da iniciativa privada e implantados no setor público sem a devida análise crítica. É necessário, entretanto, mencionar novamente a importância de modelos de gestão para as organizações públicas. Questiona-se a onipresença da importação de tecnologias gerenciais do setor privado e a dificuldade de estabelecer um ambiente e uma filosofia de trabalho que possibilitem o desenvolvimento de modelos próprios, condizentes com a realidade e a cultura organizacional do setor público. É fundamental conhecer um pouco mais do que há escamoteado nos modelos importados do setor privado, e principalmente as dimensões do controle, especialmente do nível ideológico.

A gestão da qualidade, por exemplo, pode ser percebida como um dos modelos que submetem o indivíduo a um controle cada vez mais presente e absoluto nas organizações. Por mais que os modelos gerenciais possam ser percebidos como neutros e não ideológicos, são carregados de uma carga de dominação, que não é tão facilmente percebida pelos que estão inseridos nos processos produtivos e administrativos. Há a expectativa de que, por meio de GQT (Gestão da Qualidade Total), o indivíduo esteja bem integrado às suas atividades e aos objetivos da organização. Nessa busca, há o desenvolvimento de mecanismos para maior controle do indivíduo, não se restringindo a um controle gerencial - e talvez nem isso fosse 
possível. O sistema é mantido por meio de modalidades de vigilância, que impedem não apenas o erro mas a criatividade e a confiança no funcionário. Detecta-se tanto a vigilância plena como o adestramento do indivíduo a uma forma de trabalhar previamente delineada, de modo a se alcançar prioritariamente os resultados organizacionais. Por mais que esses modelos, tais como a GQT, prometam certo nível de liberdade, de autonomia, de enriquecimento vertical da tarefa, esta existe de modo que não haja o envolvimento no estratégico.

O controle torna-se ainda mais sutil, alcançando, inclusive, a subjetividade do indivíduo, e o referido modelo passa a ser percebido como moderno, participativo e não controlador, o que é um engodo. Enfim, a GQT não reestrutura o poder nas organizações, apenas modifica o seu modus operandi. Miranda et all (2008) apresentam uma análise do controle ideológico que permeia a gestão da qualidade, a partir de alguns princípios essenciais do referido modelo: foco no cliente, liderança, envolvimento de pessoas, melhoria contínua, entre outros. Alguns elementos se destacam nessa análise crítica, tais como a remodelagem dos funcionários a partir das necessidades da organização no novo modelo de gestão; o autocontrole; o controle por meio de normas e procedimentos; o controle realizado pelos pares; as lideranças que são meros agentes reprodutores do discurso organizacional; a centralização das decisões mais relevantes; e a melhoria contínua que intensifica o ritmo de trabalho e ignora a qualidade de vida do trabalhador.

O controle e a vigilância também estão muito presentes na gestão de competências, modelo muito em voga e que visa, entre outros fatores, descrever as exigências de cada um na organização. Com o império da quantificação, da classificação e da comparação dos indivíduos na organização (Gaulejac, 2006), a gestão de competências auxilia nesse processo ao classificar as pessoas quanto às suas competências, gerando maior controle da organização sobre o indivíduo e sobre o trabalho que realiza.

Diniz e Vieira (2008) compreendem a gestão por competências como prática individualizante e de vigilância contínua. Tal modelo rompe com o conceito de categorias profissionais organizadas; privilegia bem mais os resultados que as pessoas apresentam à organização do que a qualificação que possuem e utiliza tecnologias de informação na vigilância dos funcionários de uma organização. A gestão por competências atua, dessa forma, à luz de Faria e Leal (2007, p.165), "como um instrumento da hegemonia capitalista, configurando um padrão de comportamento que hierarquiza os trabalhadores segundo o seu talento, recompensando-os ou punindo-os."

Percebe-se que o discurso hegemônico em gestão de pessoas atrai de modo incisivo as mais diversas modalidades de controle, de vigilância, de obsessão por resultados e por produtividade, entre tantos outros elementos gerenciais que preparam o indivíduo para ser cada vez mais peça dócil no processo produtivo.

É necessário buscar modelos alternativos nessa perspectiva crítica, o que implica mudanças nos processos de trabalho, na atitude e comportamento de todos os membros da organização. Tais mudanças significam intervir nos grupos de trabalho visando construir um espaço da fala e, de modo coletivo, elaborar estratégias para transformação da organização do trabalho, por meio da participação dos empregados 
na gestão das suas atividades. É por intermédio da linguagem que o empregado poderá expressar como ele vive o trabalho, como constrói e se constrói com o trabalho, como se relaciona com ele. Nesse sentido, fica reforçada a ideia de que o acesso à vivência de trabalho só pode existir se mediatizado pela palavra. Esse tipo de ação busca promover, além da prevenção do adoecimento do indivíduo, a melhoria da eficácia organizacional, do desempenho e dos serviços prestados à sociedade.

Desenvolver um novo modelo de gestão de pessoas, a partir da realidade encontrada (modelo antes de tudo situacional), é tarefa complexa e depende de inúmeros fatores, o que exige a definição de alguns pressupostos para orientar sua realização, tais como: o reconhecimento e o respeito das diferentes estruturas de funcionamento do ser humano - fundamental para a construção do sentido no trabalho. O reconhecimento é passagem obrigatória para mobilizar pessoas, renovando sua capacidade no registro da atividade e da ação. Sem o reconhecimento, não há o engajamento. Além disso, no horizonte do reconhecimento, deve estar delineado, como uma necessidade intersubjetiva, ética e técnica, o objetivo da cooperação. Os servidores devem ter claro que esse trabalho visa protegê-los de um sofrimento e que as regras têm várias dimensões: técnica, de organização das atividades; social, de ordenamento das relações entre os agentes; ética, que proporciona os valores e normas de referência; e da linguagem, pois anuncia-se no âmbito de uma prática da fala.

Esses pressupostos são fundamentados na abordagem da psicodinâmica do trabalho, que utiliza a clínica do trabalho e da ação como ferramenta para pesquisa e intervenção nos grupos trabalhistas. O momento da escuta e da fala do trabalhador é quando se alimenta a possibilidade de reconstruir processos de subjetivação do sujeito, do coletivo, no coletivo. $\mathrm{O}$ agir comunicacional que acontece nas sessões coletivas permite a intercompreensão, a visibilidade das razões e dos sentidos do trabalho, mostra o que é vivenciado pelos participantes ao realizarem suas atividades e os motivos pelos quais buscam respostas para si e para os outros

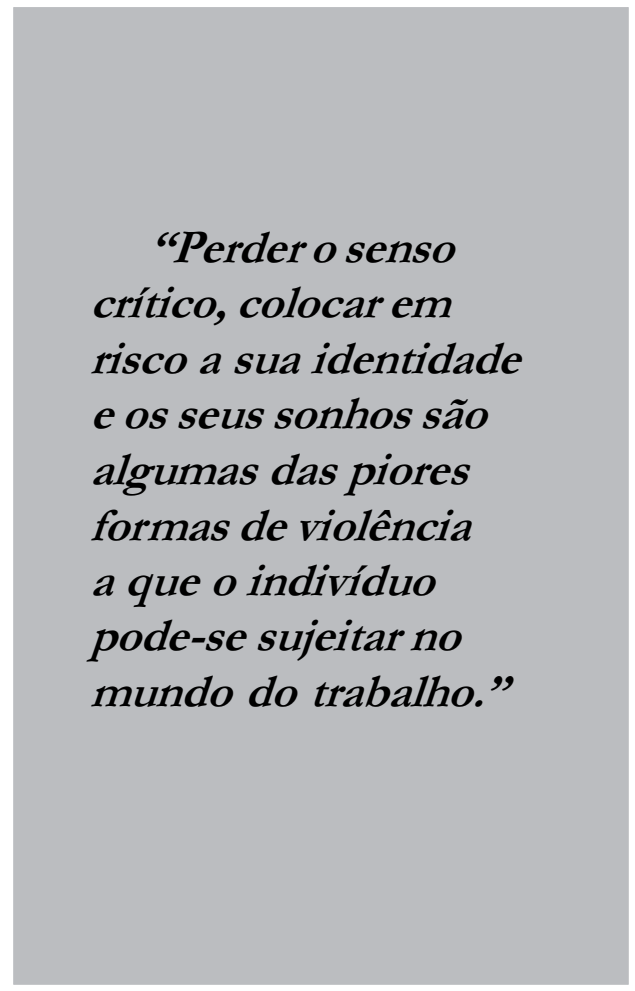

envolvidos na organização do trabalho (Heloani \& Lancman, 2004).

A clínica permite o processo de elaboração, momento em que surge a interpretação do papel desempenhado no trabalho, diminuindo as resistências para mudanças e evocando o mal-estar do vivenciado. Esses espaços da fala são fundamentais para que as trocas sejam possíveis e os planejamentos discutidos; 
também para que haja o compartilhamento de vivências e proposições de soluções, facilitando a experiência da elaboração coletiva do sentido no trabalho. A criação dos espaços organizacionais deve reconhecer e fortalecer os vínculos entre os pares pelo saber-fazer, engajando as pessoas em ações para obtenção de reconhecimento e melhorias organizacionais.

\section{Considerações finais}

O desenvolvimento da gestão de pessoas no setor público é prioridade, mas de uma gestão remodelada que garanta o alcance de resultados de modo participativo (da população e do servidor público) e que não adoeça o indivíduo e nem faça uso de mecanismos de manipulação. É necessário desenvolver uma lógica diferente da que existe no setor privado, fomentando a motivação e a criatividade, não o medo e a coerção. É mister rever todos os modelos de gestão de pessoas, tanto no contexto geral quanto no específico, no que diz respeito às funções básicas da área de recursos humanos, como seleção, treinamento, cargos e salários e gestão de desempenho. O número expressivo de indivíduos desmotivados ou apenas parcialmente motivados na administração pública deve-se não apenas a um fator específico, como o relacionado à estabilidade relativa no emprego, mas a uma miríade de elementos que levam o indivíduo à desmotivação e à apatia no ambiente de trabalho. A simples implantação de uma remuneração variável, por exemplo, pode não suprir minimamente as necessidades individuais para que haja motivação. É necessário rever o processo de seleção de pessoal, se esse tem alcançado as pessoas com real vocação para trabalhar no setor público, se a remuneração é digna, se o ambiente de trabalho é adequado, se a gestão de desempenho é justa, se há efetiva administração participativa, se o indivíduo tem a possibilidade de exercer a sua criatividade e se há espaço para que o sujeito se manifeste. Enfim, a gestão de pessoas no setor público tem um longo caminho a percorrer na criação de um modelo próprio eficiente, eficaz, cidadão e, principalmente, justo, não necessitando ser um espelho da administração privada e sim um modelo para ela.

(Artigo recebido em junho de 2009. Versão final em setembro de 2009). 


\section{Referências}

Chanlat, J.-F. Quais carreiras e para qual sociedade? Revista de Administração de Empresas. São Paulo, v.36, n.1, p.13-20, jan./fev./mar. 1996.

Diniz, P. e Vieira, A. O controle e o exercício de poder na gestão por competências: um olhar foucaultiano. Encontro Nacional de Pós-graduação em Administração, 2008.

Enriquez, E. A organiz̧ação em análise. Petrópolis: Vozes, 1997.

Gaulejac, V. Gestão como doença social. São Paulo: Idéias e Letras, 2006

Heloani, R. \& Lancman, S. Psicodinâmica do trabalho: o método clínico de intervenção e investigação. Revista produção, 14(3), 77-86, 2004.

Levy, A. Violência, mudança e desconstrução. In: AraúJo, J. e CARreteiro, T. Cenários sociais e abordagem clínica. São Paulo: Escuta; Belo Horizonte: Fumec, 2001.

Mendes, A. M. (org.). Psicodinâmica do trabalho: teoria, método e pesquisas. São Paulo: Casa do Psicólogo, 2007.

Miranda, A., Capelde, M. e Fonseca, F. Controle ideológico: uma reflexão teórica sobre os princípios que orientam as práticas da gestão da qualidade. Encontro Nacional de Pós-Graduação em Administração, 2008.

Siqueira, Marcus. Gestão de Pessoas e Discurso Organizacional. 2 ed. Curitiba: Juruá, 2009. 


\section{Resumo - Resumen - Abstract}

\section{Gestão de pessoas no setor público e a reprodução do discurso do setor privado}

Marcus Vinicius Soares Siqueira e Ana Magnólia Mendes

O objetivo deste estudo é o de estabelecer uma análise crítica do discurso contemporâneo em gestão de pessoas, verificando como discurso e prática gerencialistas se reproduzem no setor público, sem que haja a devida análise do fator ideológico que permeia a gestão privada. No contexto da idealização de modelos gerenciais, gestores públicos são ávidos em implementar modelos do setor privado, que têm uma lógica diferente da gestão do setor público. O artigo estabelece, dessa forma, a análise crítica desse processo, definindo elementos que possam inspirar a gestão de organizações públicas e respeitar as suas especificidades.

Palavras-chave: gestão de pessoas, discurso organizacional, administração pública.

\section{Gestión de personas en el sector público y la reproducción del discurso del sector privado} Marcus Vinicius Soares Siqueira y Ana Magnólia Mendes

El objetivo de este estudio es establecer un análisis crítico del discurso contemporáneo en la gerencia de las personas, siendo verificado como el discurso y la práctica gerencialistas se reproducen en el sector público sin el análisis necesario del factor ideológico que permea la administración privada. En el contexto de la idealización de modelos gerenciales, los gestores públicos son ávidos de implantar modelos del sector privado, que tienen una lógica diversa de la gerencia del sector público. El artículo establece, de esta forma, el análisis crítico de este proceso, definiendo los elementos que pueden inspirar la gerencia de las organizaciones públicas y respetar sus especificidades.

Palabras clave: gestión de personas, discurso organizacional, administración pública.

\section{Personnel management in the public sector and the reproduction of the private sector discourse \\ Marcus Vinicius Soares Siqueira and Ana Magnólia Mendes}

The goal of this article is to establish a critical analysis of the contemporary discourse in personnel management, to verify how managerial discourse and practice are reproduced in the public sector without due scrutiny of the ideological factor within the private management framework. In the context of idealization of managerial models, public managers are avid to implement private sector models, which come from a distinct logic from public sector management. The article establishes, therefore, a critical analysis of this process, defining elements which can inspire the management in public organizations and respect its specificities.

Keywords: personnel management, organizational discourse, public administration

Marcus Vinicius Soares Siqueira.

Professor doutor da Pós-Graduação em Administração da Universidade de Brasília/UnB.

Contato: marc-vs@uol.com.br

Ana Magnólia Mendes.

Professora doutora da Pós-Graduação em Psicologia da Universidade de Brasília/UnB.

Contato: anamag.mendes@gmail.com 